\title{
Between Preschool and Primary Education-Reading and Writing from the Perspective of Preschool and Primary Teachers
}

\author{
Ana Isabel Santos ${ }^{1}$ \\ ${ }^{1}$ University of the Azores, Department of Educational Science, Azores, Portugal \\ Correspondence: Ana Isabel Santos, Universidade dos Açores, Departamento de Ciências da Educação, Rua da \\ Mãe de Deus, Apartado 1422,9500-801 Ponta Delgada, Açores, Portugal. Tel: 351-962-860-810. E-mail: \\ asantos@uac.pt
}

\author{
Received: July14, 2015 Accepted: August 14, 2015 Online Published: October 28, 2015 \\ doi:10.5539/ies.v8n11p211 URL: http://dx.doi.org/10.5539/ies.v8n11p211
}

\begin{abstract}
The transition between educational levels is a process characterized by the complexity and repercussions that it represents to the future of children's education. Studies conducted in this field acknowledge the relevance of the approximation and continuity between the practices of preschool and primary teachers for children's development and learning. However, they are also unanimous in stating that an optimized transition process is far from completion. There is a lack of studies that investigate the issue of continuity between educational levels in Portugal, especially in reading and writing. To address this problem, the objective of this study is to understand the way in which preschool and primary teachers work toward a coordinated and fluid transition, particularly in the field of written language. Interviews were conducted with preschool and primary teachers, and the results reveal the different positions among preschool and primary teachers in the manner in which they conceive the transition process between these two education levels.
\end{abstract}

Keywords: educational transition, reading and writing, early childhood education, primary education

\section{Reading and Writing in the Transition between Preschool Education and Primary Education}

The transition between educational levels is widely recognized and studied as an important factor in the success of children's learning. As stated by Leppänen, Nieme, Aunola, and Nurmi (2006), the learning performed at a given level of education sets the conditions or appears to be a good predictor of the learning that will follow in the next levels. Data gathered by Brinkman, Gregory, Harris, Hart, Blackmore, and Janus (2013) have shown that literacy competencies in language and mathematics at the beginning of primary education are good indicators of children's future academic performance in these areas.

For the learning of reading and writing, the beginning of primary education is also a critical period that is particularly sensitive in children's lives. It has been understood as a key moment for children, families and teachers because it is the "beginning" of formal and more structured learning. This moment, which has a great impact on children's school lives and on the adults who interact with them, begins prior to the entry into primary education, as noted by Pickett (2005). At the preschool level, as a result of curricular changes that have taken place in the area of reading and writing over the last few decades, the development of literacy competencies has begun to receive greater weight and pressure to transition children with a set of competencies that are essential for their future academic performance.

In Portugal as in other countries, this reality is related to a change in recent decades in the paradigmatic approach to written language, oriented by investigations in this study area that have pointed toward the knowledge and competencies that children, even before entering preschool education, already have. There has been a gradual shift from the perspective that reading and writing are the intervention area of primary teachers to the perspective of emergent literacy in early childhood education, which is not always fully understood and faithfully implemented in preschool (Guimarães \& Youngman, 1995; Santos, 2007; Santos \& Alves-Martins, 2014). Similar to the study conducted by Ferreiro (1997), recent studies have indicated the presence of two different perspectives on thinking about reading and writing in the pedagogical practices of Portuguese teachers. First is the reading readiness perspective, which is associated with the idea that for the child to learn reading and writing, a set of competencies identified as prerequisites must be developed. These competencies are acquired through activities related to audio-visual discrimination, memory, vocabulary development, listening ability, visual-motor 
skills, and the knowledge of letters and their respective sound values. This perspective involves teaching writing as a transcription technique, and it is somewhat focused on the adult as the person who has knowledge of what it means to read and write. Second is the emergent literacy perspective, which is child-centered and focuses on the needs and interests of children. This perspective considers the child's contextualized use of writing as the starting point for learning, gives legitimacy to the conventional reading and writing behaviors of children, respects what they know, and encourages the teacher to create environments that are rich in reading and writing, expanding the opportunities for children's contact with diverse literacy experiences (Guimarães \& Youngman, 1995; Mcmahon, Richmond, \& Reeves-Kazelskis, 1998; Miller, 2001; Santos, 2007).

In the teacher's pedagogical practice, these same studies have demonstrated the existence of a set of contradictions and inconsistencies in the manner in which teachers think about written language at the preschool level of education. According to those studies, these contradictions occur, for example, between the types of activities that teachers claim to implement, how they approach writing, and the competencies that they seek to develop in children, between the existing curricular guidelines and the manner in which they interpret them or between the role of writing in the education of children and the age considered key to the beginning of a study in this area. These inconsistencies reveal implications at the level of the teacher's pedagogical practices that have with important repercussions related to the involvement of children in literacy events. Regardless of the manner in which each teacher views his or her own pedagogical intervention, at the end of the 1990s, based on the emergence of the Curricular Guidelines for Preschool Education (Ministry of Education, 1997) and more recently with the curricular revision of the Portuguese Program for Primary Education (Ministry of Education, 2009), it is expected that the teaching and learning processes of reading and writing are oriented, in the actual pedagogical practice of these preschool and primary teachers, toward the understanding of what reading and writing are and toward their functional use and significance.

Specifically, in terms of transition from one educational level to the other, both documents reflect a set of intentions, more or less explicit, concerning educational continuity, what preschool and primary teachers should pay attention to, and the conception and implementation of strategies that aim at the creation of favorable conditions for a successful transition. These terms are clearly explicit in the Curricular Guidelines for Preschool Education (Ministry of Education, 1997, p. 28), which state, "it is also the teacher's role to provide the conditions for each child to successfully learn in the next phase; the teacher shall also be responsible, in collaboration with parents and in conjunction with colleagues of the primary school, for facilitating the transition of the child to compulsory schooling". In the Portuguese Program for Primary Education (Ministry of Education, 2009), teachers are requested to pay attention to the learning that children have already acquired in their passage through preschool education.

In terms of studies on the process of educational transition, from the perspective of the pedagogical practices of literacy between preschool and primary education, there are few studies that explore in-depth the topic of educational transition. The studies that do address the issues of transition between these two levels of education point to the importance of the proximity, continuity, and types of practices of preschool and primary teachers as a key aspect of children's learning and development (Ahtlo et al., 2011; Chun, 2003; Early, Pianta, Taylor, \& Cox, 2001; Einarsdottir, 2006; Margetts, 2002). The authors of these studies are unanimous in stating that in most cases, there are discontinuities between the two levels of education that occur at the level of the pedagogical beliefs and practices of these teachers.

These discontinuities are the result of the preschool and primary teachers' training and a long "tradition" related to the manner in which preschool and primary teachers conceive their role. They have consequences in terms of the working methods in either context. In the concrete terms of intervention, as concluded by Early et al. (2001), preschool is the phase of the highest number of practices oriented to the transition process, even though what is performed remains far from achieving the optimization of this process. Einarsdottir, Perry, and Dockett (2008) present similar conclusions. They stress that although teachers conceive the process as important and although they have implemented some activities, namely, visits of preschool children to primary education classrooms, there is no continuity at the levels of curricula and pedagogical practices. As Margetts notes (2002), efficient transition processes should extend far beyond simple visits. They must include the gradual preparation of children and families, based on a logic of peer continuity, the expectations of children and teachers, the curricula themselves, and the maintenance of comprehensive communication processes among all individuals involved. As stated by Dockett and Perry (2004), the reason is that teachers, parents, and children have different perspectives, experiences, and expectations related to the transition that influences the manner in which the transition process will be realized.

Based on this scenario and because of a lack of Portuguese studies that address the issues related to the transition 
between preschool and primary education, particularly in the context of reading and writing, it is imperative to attempt to understand how such continuity is or is not present in Portuguese schools from the perspectives of the preschool and primary teachers involved.

For this reason and to search for clues that will allow a broader and more in-depth study to be conducted in the future, this investigation was conducted on how preschool teachers and primary school teachers design and implement strategies that are oriented toward the transition process in an attempt to identify the aspects that convey to them this logic of continuity and coordination.

\section{Method}

The primary objective of this study is to diagnose the situation that will allow us to subsequently expand the study to a larger group of preschool and primary teachers. A total of 10 interviews were conducted, five with preschool teachers and five with primary teachers, to gather information on these professionals' opinions on what their role should be and on the work that is performed within the scope of their interventions to facilitate a continuous and coordinated transition process.

\subsection{Data Collection Instrument}

The interview was used as an instrument for data collection. The purpose was to access the thinking process of the participants to "... define the representations, values, and standards systems conveyed by an individual" (Albarello et al., 1995, p. 89).

The interview was organized into two blocks of questions. The first block contained general questions that allowed briefly characterizing the teachers surveyed. It covered topics such as age, gender, years of teaching experience, initial training and continuing education, pedagogical model followed, the grade she/he teaches at the time of the interview, and previous experience teaching 1st-year classes in primary education.

The second block focused, in part, on pedagogical issues related to written language in kindergarten and in the primary education, including the following: goals, differences in the manner in which writing should be approached in either context, ways to operationalize the work of the teachers in this area, and the competencies that children should acquire at either school level. The other questions in this block were related to the transition in writing. It explored the reasons why preschool and primary teachers invest or not in a transition process, the type of work they think should be performed, the type of work that actually occurs, the competencies that children should acquire for the transition process to be fluid, and the identification of those responsible for this process and their role.

\subsection{Participants}

Five preschool teachers and five teachers of primary education were interviewed. In Portugal, the preschool teachers working with children from 3 to 6 years and the primary teachers with children from 6 to 10 years old. The five preschool teachers interviewed are all female, aged between 31 and 45, and had taught on average for nine years. Four of the teachers hold a licentiate degree, whereas one was educated under the old system for primary teacher training but acquired additional scientific and pedagogical training that gave her a licentiate degree. Four of these preschool teachers stated that they did not follow a particular pedagogical model, and one noted working with project-approach. The five primary teachers interviewed are aged between 26 and 36; four are female and one male and had taught on average for four years. Four hold a licentiate degree, and one has a graduate degree. Concerning the pedagogical models followed in their educational practices, one declared not following any pedagogical model, another noted following a traditional perspective, and 3 indicated a constructivist perspective. Of these 5 primary teachers, 3 taught the 1 st year at the time of the interview, and the remaining two had taught the 1st year in previous school years.

\section{Results}

\subsection{Written Language in Preschool Education and in the Primary Education}

Asked about the importance of reading and writing in preschool education and about what it means to work on written language at this educational level, all preschool teachers and four of the five primary teachers stated that reading and writing are essential in early childhood education. The primary teacher who stated that written language was not an area for investment on the part of the preschool teacher could not directly explain his opinion. However, later in the interview, he manifested some unawareness regarding preschool education work and stated, "Is reading approached in early childhood education? Hum ... I don't know. I don't know how to answer because I cannot differentiate, because I never watched a preschool classroom."

For those who considered the work in this field important at the level of preschool education, the objectives or 
the reasons for this importance are related, in the case of the preschool teachers, with the following: the discovery of the function of writing (one teacher), the discovery of writing itself (two teachers), encouraging its playful character (one teacher), and work oriented toward phonemes and orthography (one teacher). In the case of the primary teachers, the reasons given are as follows: creating a taste for reading and writing (one teacher), encouraging reading and writing (one teacher), the oral exploration of language (one teacher), and addressing the needs and interests of the children (one teacher).

The ideas of preschool and primary teachers do not seem to differ considerably in terms of the approach to reading and writing when trying to distinguish between the work that must be performed in preschool education and the work that must be occurs in the primary education. For the preschool teachers, the difference between the work at the two levels resides in the following: the fact that there is a formal curriculum in primary education and a curriculum that is more focused on discoveries in preschool education (three teachers); the work in primary education is more oriented toward writing full texts, and the work in preschool education is more inclined toward writing words (one teacher) and toward the existence of a set of prerequisites for preschool education, in contrast to the formal curriculum in primary education (one teacher). From the teachers' perspective, preschool education means awakening learning, as opposed to the more formal work in primary education (two teachers) or the work focused on orality in preschool education versus the work focused on the development of phonological awareness in primary education (one teacher). Interestingly, one teacher interviewed believes that the logic of approximating the work that is performed in the two levels is reasonable, noting that, "Today, there is an initial approach to the primary education that is similar to that in preschool."

Still focusing on the development and learning of written language, the preschool and primary teachers were asked whether there is a right time to begin working on reading and writing, and if so, when and why, in addition to when children begin to develop reading and writing skills.

For three preschool teachers, reading and writing should start to be worked on preschool education; for one it should happen very early, even babies; and for a fifth teacher, this work should start when children are prepared and show some interest in this area. Primary teachers supposed that reading and writing should begin to be worked on in primary education, when the child enters the 1st year (two teachers); between preschool and eight years of age (one teacher); or that there is no right time to initiate this work (two teachers).

The reasons for defining or not defining a particular time to start working on written language, according to the preschool teachers, are related to the benefits of early contact with written material (two teachers), the respect for the child's interest (one teacher), and the maturity of the child (one teacher). One of the teachers did not give reasons for her answer. Primary teachers explain their answers, noting the competencies that children already have at a given point in their school path (one teacher), the maturity of the children (one teacher), and the fact that the primary education is the right time (one teacher). Two teachers claim that there is no right time because it is difficult to define when this time is in terms of each child's development.

Concerning the time children when begin to develop reading and writing competencies, the preschool teachers state that they start developing it at two years of age (one teacher); at three or four years of age (two teachers), at seven years of age (one teacher), or that there is no specific age (one teacher). For the primary teachers, children begin to develop reading and writing skills from an early age (two teachers) to five years of age (one teacher), in the 1st year of the primary education (one teacher), or it depends on each child (one teacher).

Although preschool teachers concern themselves with and work on written language in preschool education, the inconsistency in the thinking of these teachers and primary teachers is worrying. The lack of awareness of one of the primary teachers regarding the preschool reality is also disturbing. This situation may certainly be an obstacle to the implementation of a transition process and successful pedagogical continuity. Even recognizing these inconsistencies as inherent to the very nature of the teacher, as some studies have demonstrated (Guimarães \& Youngman, 1995; Mcmahon, Richmond \& Reeves-Kazelskis, 1998; Miller, 2001), they reveal inconsistent ways of thinking that need a more grounded rationale, as has also been indicated by Santos (2007).

Looking at these data, it seems evident that preschool teachers work more closely with the emergent literacy perspective, given that they identify activities that promote the discovery of writing and its function. However, this apparent proximity to a modus operandi aligned with the latest perspectives on the field and the legal guidelines clashes with the definition of specific times for starting a pedagogical intervention in this area. It also collides with an approach that is sharply focused on the adult. Moreover, it reveals gaps in the manner in which these teachers think about reading and writing, a situation that has also been identified in similar studies (Guimarães \& Youngman, 1995; Mcmahon, Richmond \& Reeves-Kazelskis, 1998; Miller, 2001; Santos, 2007).

Regarding the way of thinking of the primary school teachers, only one claimed to have adopted an approach 
that is related to an emergent literacy perspective. Most teachers clearly revealed that they follow a more "traditional" logic of teaching reading and writing. This logic is related to the perspective of reading readiness, and similar to the perspective of the preschool teachers, it indicates a specific time for starting to work in this area that roughly coincides with the beginning of compulsory schooling.

In general, the preschool and the primary teachers had different opinions concerning the work performed in preschool education versus primary education, identifying the former with "playful" and informal contact with writing, with some references to its functional use. The latter was identified with "formal" education, focused on national curriculum guidelines, clearly marking the difference between the two levels. These differences were explained based on the maturity of the child or the child's preparation for learning reading and writing, which have been clearly associated with the reading readiness perspective (Ferreiro, 1997).

\subsection{The Transition between Preschool Education and the Primary Education in Reading and Writing}

Preschool and primary teachers were asked about the relevance of work specifically oriented toward transitioning children between the two levels of education. To all of the interviewed preschool teachers, it made sense to have work designed for the transition of children in the field of written language to develop the basic notions to enable them to prepare for the transition (four teachers) and for the child to feel safe (one teacher). By contrast, two out of the five primary teachers argued that it did not make sense to have this type of work because there are children who do not attend preschool education and because reading and writing should only be worked on in the primary education. The remaining three teachers considered this type of work to be important because it enables the development of competencies (two teachers) and facilitates the work to be performed in the primary education (one teacher).

Assuming that there will be work designed for the transition in written language, the following question is asked: what type of work should be performed in preschool education and in the primary education from the perspective of these teachers?

For the preschool teachers, preschool education should include the following: preparation activities, in particular worksheets; the identification of one's own name; storytelling; joint activities with the primary school; the creation of situations that involve the functional use of reading and writing; the exploration of the conceptual, figurative, and functional aspects of writing language; reading by the adult; and contact between the preschool teacher and the primary teacher, that includes the preparation of an assessment report by the preschool teacher to be delivered to the primary teacher. Relative to the primary education, the preschool teachers believe should be made visits and presentation of works in the preschool classes; a diagnostic assessment of the student should be performed; a particular teaching method should be used; and one teacher indicated not knowing what to expect the teachers to do.

For primary teachers, the type of work that must be implemented in preschool education to favor the children's transition in reading and writing must take into account the creation of diversified activities, contact with books, and experience with the contextualized and functional use of written language. Two of the teachers surveyed state that no work in this regard should be performed. In the primary education, one of the teachers believes that different games should be performed and that space and time should be organized similarly to in preschool education. For the remainder, the teacher must be more rigorous and demanding, and he/she must use a particular method for teaching reading or should not perform any work to facilitate the transition.

Based on the opinions of preschool and primary teachers regarding what should be done, the next question asked relates to what they do in their practices to facilitate the transition process in written language.

The preschool teachers interviewed claim to conduct visits with the children to the primary school, the implementation of activities in the school library, reading and writing for the children, promoting the use of record boards (attendance board, time board), and following a method for teaching reading. They also claim to use the various work areas in the room, to show devices with letters, and to talk to the teacher who will teach the children in the primary school. Regarding the primary teachers, one teacher claims to use role playing games, reading to the children (adult reading), functional reading, and organizing the classroom space with characteristics that are similar to those in a preschool room. The remaining teachers who claim to use specific models to teach reading do not note any link to preschool education.

Assuming that work will be designed to foster the transition process, especially by preschool teachers, the teachers were asked to explain what is considered to be the best time for this process to begin to occur and what competencies should children have developed in the domains of reading and writing to transition into the primary education. 
For the preschool teachers, the transition should occur during preschool education, with some emphasis on the last year (two teachers) or when the child is prepared (two teachers). For one teacher, there is no right time. The latter idea is also shared by three of the primary teachers interviewed. The fourth primary teacher believes that the transition should be worked on at the end of preschool education, and another teacher holds that this process can only occur in the primary education.

Concerning the reading and writing competencies that children should have developed when transitioning to the primary education, the preschool teachers listed the following: development of fine motor skills; drawing letters; autonomy; enjoying learning; recognizing their own name; distinguishing letters from numbers; knowing the conventional spatial orientation of reading and writing; recognizing letters; distinguishing letters from words and phrases; and orally dividing words into syllables. One of the five teachers interviewed failed to list a particular competency that children should develop.

From the perspective of the primary teachers, when transitioning to the primary education, children: should be able to interpret images, must have developed core competencies (writing their own name and identifying colors), must have developed an interest for reading and writing, should understand the meaning of the text while reading, and should have developed fine motor skills. One of the teachers states that "early childhood teachers, of course, will have a greater capacity to answer this question."

Finally, the teachers were asked about the person or persons responsible for the children's transition process and the role of these individuals.

From the perspective of the preschool teachers, the individuals responsible are the parents, the preschool teacher, the primary teacher, and the child (three teachers) or the parents, the preschool teacher, and the primary teacher (two teachers). It is the role of parents to provide resources, read stories, and encourage the child to read and write. The child is responsible for demonstrating a willingness to learn, and the teachers are responsible for teaching, supporting, and reading stories.

From the perspective of the primary teachers, the main individuals responsible for the process are the parents, and the preschool and the primary teachers (three teachers); or the preschool and the primary teachers (two teachers). The role of parents and teachers is to work as a team (three teachers). Parents and teachers should promote the child's intellectual growth and assist in the acquisition of core competencies (holding a pencil, for example); specifically, the parents are responsible for helping and encouraging the child.

A careful analysis of these data shows that without question, the transition in written language between preschool and primary education is considered essential for most of the teachers interviewed. However, some primary teachers believe that the process is not necessary because they consider that reading and writing are aspects to be worked on only at the level of primary education. This position is not far from the findings in the literature, which point to a greater level of concern for and proactivity in the transition process on the part of preschool teachers compared to primary teachers (Early et al., 2001; Einarsdottir, Docket \& Perry, 2008). Indeed, most preschool and primary teachers indicate that preschool education is the appropriate time during which to initiate more systematic work toward the transition, and preschool teachers seem to be held implicitly responsible for the entire process.

In general, when considering the transition between the two education levels, the goal of preschool and primary teachers is to train children for the next level. This training should be based more on a logic driven by the specific competencies that children must acquire than on a logic of broad and cross-disciplinary preparation that extends beyond specific activities. These goals are in line with the types of activities that preschool and primary teachers identify as important for implementation in pedagogical practice, namely, activities that are mostly conducted in preschool classroom, with occasional visits to the primary school. This conclusion is similar to what is reported by Margetts (2002).

The contrast between the activities that the teachers consider should be implemented and those that they claim to perform in their teaching practice to promote the transition is curious because there is a slight mismatch between them. If the activities that should be performed are based on the children's departure from their classroom for a visit to the primary education, then the activities implemented are fundamentally centered on the preschool classroom. However, only one primary teacher identifies some strategies to address preschool education in his or her teaching practice, and these strategies are focused solely on this teacher's own classroom. Greater effort on the part of preschool teachers in performing activities oriented toward a more fluid transition is again explicit; however, it remains very poorly diversified and excessively restricted to the classroom context.

Accordingly, we cannot fail to highlight, even based on the small sample of teachers from both levels, the lack of 
awareness shown by some teachers in relation to the others' reality. That is, the preschool teacher is unaware of what the primary teacher can do, and the primary teacher does not know what type of intervention is up to the preschool teacher. This fact lends poor support to the establishment of transition strategies for a real coordination and continuity between the two levels of education.

With regard to the competencies to be emphasized in pedagogical work oriented toward the transition between preschool and primary education in reading and writing, the preschool and primary teachers are in agreement. They mainly indicate the competencies of reading readiness and pay less attention to emergent literacy activities that lead children to think about writing. This partly contradicts the goals that preschool teachers listed in the first part of the interview to explain their pedagogical intervention.

Finally, when examining the role of participants throughout the transition process, the reduced role that the child ends up playing, becoming a mere passive consumer of activities proposed by preschool and primary teachers, warrants attention. Especially for the primary teachers, the transition is reducible to the promotion of specific academic competencies, which teachers and parents are responsible for. There is no particular aim to facilitate the transition process between levels; instead, only accomplishing what is expected is the role of each of the individuals in the learning process of children. There does not appear to be a deep involvement with the logic proposed by Dockett and Perry (2004) or Margetts (2002).

\section{Conclusions}

The results presented here are indicative of the different positions among preschool and primary teachers on the manner in which they perceive the transition process between these two levels of education. However, the identification of intervention strategies aimed at the development of competencies related to readiness for reading and writing, which are distant from the emergent literacy perspective that should prevail and sharply focused on the adult, seems to be a common denominator in how these teachers think. Furthermore, there are discontinuities in the manner in which preschool and primary school teachers conceive the transition, and preschool teachers are more proactive in this regard. For the primary teachers, although important, the transition is relegated to preschool education, which indicates their apparent disengagement with it. In general and particularly in preschool education, the transition process, complex in the types of interventions and interventionists, is reduced to singular interventions. This aspect is extensively reported in the bibliography of the specialty described above.

Finally, it is crucial to draw conclusions from the study conducted to understand future implications. In this respect, on one hand, it seems essential to deepen this study and extend its scope to better understand how the transition actually occurs. This broadening refers to the inclusion of not only more preschool and primary teachers but also parents and children so that, as much as possible, we can have a comprehensive view of the situation. On the other hand, it is necessary to invest in the training of teachers in the context of the approach to written language and specifically in the transition between the two levels of education. It is also necessary to understand this transition as a continuous process and to call the attention of preschool and primary teachers to the importance of this process and to the advantage of adopting diverse strategies of action that allow a closer relationship between the two levels of education.

\section{References}

Ahtola, A., Silinskas, G., Poikonen, P.-L., Kontoniemi, M., Niemi, P., \& Nurmi, J.-E. (2011). Transition to formal schooling: Do transition practices matter for academic performance? Early Childhood Research Quarterly, 26(3), 295-302. http://dx.doi.org/10.1016/j.ecresq.2010.12.002

Albarello, L., Digneffe, F., Hiernaux, J.-P., Maroy, C., Ruquoy, D., \& Saint-Georges, P. (1995). Práticas e Métodos de Investigação em Ciências Sociais [Practice and Research Methods in Social Sciences]. Lisboa: Gradiva.

Brinkman, S., Gregory, T., Harris, J., Hart, B., Blackmore, S., \& Janus, M. (2013). Associations between the early development instrument at age 5, and reading and numeracy skills at ages (8, 10 and 12): A prospective linked data study. Child Indicators Research, 6(4), 695-708. http://dx.doi.org/10.1007/s12187-013-9189-3

Chun, W. N. (2003). A study of children's difficulties in transition to school in Hong Kong. Early Child Development and Care, 173(1), 83-96. http://dx.doi.org/10.1080/0300443022000022440

Dockett, S., \& Perry, B. (2004). What makes a successful transition to school? Views of Australian parents and teachers. International Journal of Early Years Education, 12(3), 217-230. http://dx.doi.org/10.1080/0966976042000268690 
Early, D. M., Pianta, R. C., Taylor, L. C., \& Cox, M. J. (2001). Transition practices: Findings from a national survey of kindergarten teachers. Early Childhood Education Journal, 28(3), 199-206. http://dx.doi.org/10.1023/A:1026503520593

Einarsdottir, J. (2006). From Pre-school to Primary School: When different contexts meet. Scandinavian Journal of Educational Research, 50(2), 165-184. http://dx.doi.org/10.1080/00313830600575965

Einarsdottir, J., Perry, B., \& Dockett, S. (2008). Transition to school practices: Comparisons from Iceland and Australia. Early Years: An International Research Journal, 28(1), 47-60. http://dx.doi.org/10.1080/09575140801924689

Ferreiro, E. (1997). Alfabetización-Teoría y Práctica [Alphabetization-theory and practice]. México: Siglo Veintiuno.

Guimarães, A. S., \& Youngman, M. (1995). Portuguese preschool teachers' beliefs about early literacy development. Journal of Research in Reading, 18(1), 39-52. http://dx.doi.org/10.1111/j.1467-9817.1995.tb00067.x

Leppänen, U., Nieme, P., Aunola, K., \& Nurmi, J. (2006). Development of reading and spelling Finnish from preschool to Grade 1 and Grade 2. Scientific Studies of Reading, 10(1), 3-30. http://dx.doi.org/10.1207/s1532799xssr1001_2

Margetts, K. (2002). Transition to School-Complexity and Diversity. European Early Childhood Education Research Journal, 10(2), 103-114. http://dx.doi.org/10.1080/13502930285208981

Mcmahon, R., Richmond, M. G., \& Reeves-Kazelskis, C. (1998). Relationships between kindergarten teachers' perceptions of literacy acquisition and children's literacy involvement and classroom materials. The Journal of Educational Research, 91(3), 173-182. http://dx.doi.org/10.1080/00220679809597538

Miller, L. (2001). Shaping early childhood through the literacy curriculum. Early Years, 21(2), 107-116. http://dx.doi.org/10.1080/09575140125089

Ministério da Educação. (1997). Orientações Curriculares para a Educação Pré-Escolar [Curriculum Guidelines for Preschool Education]. Lisboa: Ministério da Educação [Ministry of Education].

Ministério da Educação. (2009). Programa de Português do Ensino Básico [Portuguese Program for Basic Education]. Lisboa: Ministério da Educação [Ministry of Education].

Pickett, L. (2005). Potential for play in a primary literacy curriculum. Journal of Early Childhood Teacher Education, 25, 267-274. http://dx.doi.org/10.1080/1090102050250310

Santos, A. I. (2007). A abordagem à leitura e à escrita no jardim-de-infância: Concepções e práticas dos educadores de infância [Approach to reading and writing in the preschool education: Beliefs and practices of preschool teachers] (Unpublished doctoral dissertation). University of the Azores, Angra do Heroísmo, Portugal.

Santos, A. I., \& Alves-Martins, M. (2014). Conceções dos educadores portugueses sobre a linguagem escrita: Um estudo de caso [Portuguese preschool teachers beliefs about written language: a case study]. Revista de Estudios e Investigación en Psicología y Educación, 1(1), 26-34. http://dx.doi.org/10.17979/reipe.2014.1.1.19

\section{Copyrights}

Copyright for this article is retained by the author(s), with first publication rights granted to the journal.

This is an open-access article distributed under the terms and conditions of the Creative Commons Attribution license (http://creativecommons.org/licenses/by/3.0/). 